\title{
Software Timing Problem
}

National Cancer Institute

\section{Source}

National Cancer Institute. Software Timing Problem. NCI Thesaurus. Code C92117.

Problems that results from the incorrect sequencing or activation of software modules. 